${ }^{1} \mathrm{MS}$, PhD student. Department of Dentistry, State University of Ponta Grossa. Ponta Grossa, Paraná, Brazil.

${ }^{2}$ DDS, MS, PhD. Professor. Departament of Dentistry, State university of Ponta Grossa. Ponta Grossa, Paraná, Brazil.

${ }^{3}$ DDS, MS, PhD. Professor. Department of Dentistry, State University of Ponta Grossa. Ponta Grossa, Paraná, Brazil.

¿DDS, PhD. Professor. Department of Dentistry, State University of Ponta Grossa. Ponta Grossa, Paraná, Brazil.

${ }^{5}$ DDS, MS, PhD. Professor. Department of Dentistry, State University of Ponta Grossa. Ponta Grossa, Paraná, Brazil.

${ }^{6} \mathrm{DDS}, \mathrm{MS}, \mathrm{PhD}$. Professor. Department of Dentistry, State University of Ponta Grossa. Ponta Grossa, Paraná, Brazil.

Corresponding author: Rua Carlos Cavalcanti, 4748 , Bloco M, Sala 64A - Uvaranas Ponta Grossa, PR, Brazil, 84030-900: email: giomongruel@gmail.com

Received: July 27, 2018

Accepted: October 09, 2018

\section{Influence of different burs and acid ultrasonic agitation on the bonding of fiber posts to root dentin}

\author{
Julio Cezar Chidoski-Filho', Giovana Mongruel \\ Gomes $^{2}$, Bruna Fortes Bittencourt ${ }^{3}$, Alessandra Reis ${ }^{4}$, \\ Osnara Maria Mongruel Gomes ${ }^{5}$, João Carlos Gomes ${ }^{6}$
}

Aim: The objective is to evaluate the influence of different burs used to prepare the root canal space and acid ultrasonic agitation on bond strength (BS) between glass fiber posts (GFP) and root dentin. Methods: After endodontic treatment, the root canal spaces of 36 extracted human canines were prepared, according to the rotary instrument used $(n=18)$ : carbide bur $(C B)$, provided by the post manufacturer and a diamond bur (DB). In both groups, the fiber posts were cemented with the adhesive system Ambar and resin cement Allcem, following the manufacturer's instructions. Previously to the cementation procedures, the groups were subdivided into 2 groups $(n=9)$, according to the phosphoric acid application mode: conventional etching (CE) and active etching (AE), performed by ultrasonic tip, both for $15 \mathrm{~s}$. Before the cementation procedures and after the acid application, 1 root of each group was randomly selected for ultrastructural morphological evaluation by SEM. After 1 week of the cementation, 8 specimens per group were transversely sectioned into six 1-mm thick slices, the root canal regions (cervical, medium and apical) were identified and the push-out test was performed to evaluate BS. Data were analyzed by 3-way ANOVA and Tukey test $(a=0.05)$. Results: The results showed that the cross-product interaction of all factors was significant $(P=0.035)$. Higher bond strength values were obtained when a DB with conventional etching, instead of $\mathrm{CB}$, was used to prepare the root post space. Conclusion: It may be concluded that the use of diamond burs with conventional etching yields high BS values in all root canal thirds.

Key-words: Cementation. Post and core technique. Resin cements. 


\section{Introduction}

It is consensual that the best materials to restore endodontically treated teeth are those with elastic modulus like dentin ( $18 \mathrm{GPa}$ ) such as resin cements (6.8 to $10.8 \mathrm{GPa}$ ), composite resins $(5,7-25 \mathrm{GPa})$ and glass fiber posts $(16-40 \mathrm{GPa})^{1,2}$. Such materials with similar elastic modulus reduce stress concentration on the root dentin and the percentage of unrecoverable failures due to root fracture ${ }^{3,4}$. However, even using materials with appropriate mechanical properties, fiber post failure due to debonding is still a clinical problem 5 .

The retention of glass fiber posts depends on effective adhesion between the adhesive system, the resin cement and the dentin substrate; nevertheless this is a very challenging operative step ${ }^{6}$. Heterogeneity of the dental root substrate, difficulties in fiber post adjustment, different presentations of adhesive systems and resin cements and variations in application techniques play a role in the complex protocol6,7.

Apart from these factors, the impact of an important clinical step has been neglected in the bonding protocol of fiber posts. Commonly, the root canal post space is prepared with carbide burs provided by the post manufacturer. However, it has already been demonstrated that carbide burs usually provide lower bond strengths to coronal dentin than diamond burs ${ }^{8,9}$. The smear layer different patterns may be responsible for such finding. Diamond burs produce a loosely organized smear layer and thicker than that produced by carbide burs, however, although they are thicker, they can be more easily removed, which affects the way adhesives interact with the substrate 10-12. $^{\text {. }}$

Additionally, this may be even more significant depending on the type of adhesive strategy selected for fiber post bonding. Although conventional acid etching removes the smear layer, this is usually not completed at apical thirds of root canals due to the difficult access to this area when using an etchant gel for acid etching. To enhance the etching ability, the acid should be agitated on dentin, which may increase bond strength values?

A previous study demonstrated that on root dentin the active application with an endodontic needle ensured a complete smear layer removal from the dentin walls with increase in bond strength values ${ }^{13}$. The use of ultrasonic agitation with various irrigating solutions also contributes for smear layer removal and may be a useful approach when dealing with either thin or thick smear layers ${ }^{14,15}$.

To the extent of the author's knowledge, no study has so far evaluated whether rotary instruments (carbide vs. diamond burs) with the agitation of the etchant during acid etching can affect the bonding performance of fiber posts to root canals. Therefore, the objective of this study was to evaluate the influence of the rotary instrument used to prepare the post space and the application mode of the etchant on the bond strength between glass fiber post and root dentin. The null hypotheses were that the type of 1) rotary instrument or 2) ultrasonic agitation would not influence the push-out bond strength values of fiber posts to the root canal. 


\section{Materials and methods}

The Ethics Committee of the Local University approved this study (protocol \#256.753). Thirty-six extracted human maxillary canines were stored in distilled water at $4^{\circ} \mathrm{C}$ and used within 6 months after extraction. Teeth that exhibited clinical signs of caries, root resorption, cracks, or fractures were excluded. Additionally, all teeth had a root length of $14 \pm 1 \mathrm{~mm}$, measured from the cement-enamel junction (CEJ).

The teeth were transversally sectioned $1 \mathrm{~mm}$ above the CEJ by using a low-speed diamond saw (Isomet 1000; Buehler) under constant irrigation. Canal exploration was performed with \#10K files (Dentsply Maillefer, Baillegues, Switzerland) and irrigation with $1 \%$ sodium hypochlorite. Apical enlargement was performed until \# 40 and crown-down technique until \# 55 files. Irrigation was performed after every change of instrument with $1 \mathrm{~mL} 1 \%$ sodium hypochlorite. The canals were neutralized with saline solution and final irrigation with 17\% EDTA for 3 min. The roots were dried with paper points (Dentsply Maillefer, Baillegues, Switzerland) and filled with resin-based sealer (AH Plus; Dentsply) and tapered with gutta-percha points (Tanari) using the warm vertical condensation technique, leaving only $4 \mathrm{~mm}$ apical seal.

The post space walls were evaluated for the presence of any residual gutta-percha with radiographs (Kodak Ultra; Eastman Kodak). The root access was temporarily filled with glass ionomer cement (Vitro Fil; DFL), and stored in $100 \%$ relative humidity (Eppendorf tubes, supported by gauze soaked in distilled water) at $37^{\circ} \mathrm{C}$ for 1 week.

After this period, the roots were randomly divided into 2 groups $(n=18)$, according to the rotatory instrument used to prepare the post space: $C B$ - tungsten carbide bur provided by the glass fiber post manufacturer (Whitepost DC \#0.5; FGM) and DB diamond bur (\#4137; KG Sorensen) in a low-speed handpiece. After 4 preparations, the burs were substituted. The root canals were irrigated with $10 \mathrm{~mL}$ distilled water and dried with air for $3 \mathrm{~s}$ and paper points.

The groups were then subdivided into 2 groups ( $n=9)$, according to the acid application mode: $\mathrm{CB}+$ conventional etching with phosphoric acid for $15 \mathrm{~s}$; $\mathrm{CB}+$ active etching with phosphoric acid for $15 \mathrm{~s}$ with an ultrasonic tip (Tip G3 with a $0.03 \mathrm{MHz}$ frequency - Ultrasonic Jet Sonic; Gnatus); DB + conventional etching; DB + active etching as reported for $\mathrm{CB}$. The cementation procedures were performed with Ambar adhesive system and All-Cem Core dual resin cement, following the manufacturer's instructions (FGM). The fiber posts were previously cleaned with $70 \%$ alcohol for $5 \mathrm{~s}$.

All light-curing procedures were performed with a LED light-curing device (Radii Plus; SDI Ltd) using a $1200 \mathrm{~mW} / \mathrm{cm}^{2}$ power density.

Before the cementation procedures, immediately after the acid application, one root of each group $(n=1)$ was randomly selected for ultrastructural morphological evaluation of the quality of the smear layer obtained after the preparation of root canals with the different burs and acid application modes. To facilitate root fragmentation and consequent exposure of the root dentin from the post space, 2 longitudinal grooves orientation (buccal and lingual faces) were performed in the outer root surface with a 
double-sided diamond saw adapted to a low speed handpiece. Additionally, 2 transverse grooves on the anatomical neck were performed not reaching the inner post space. After root space preparation, according to the experimental groups, the roots were cleaved longitudinally and transversely using a chisel into 2 hemi-sections to expose the entire length of the root canal.

The samples (hemi-sections) were then dehydrated, covered with gold, set in metal matrix and taken to a scanning electron microscopy (SEM; VEGA3 TESCAN). Three arbitrary images $(\times 2000)$ were taken from each root canal third (cervical, middle and apical) of each hemi-section.

After 1 week of the cementation procedures, the 8 remaining roots per group were placed in separate polyvinyl chloride tubes and embedded in acrylic resin (Duralay; Reliance Dental Mfg). The portion of each root containing the root slice with the bonded fiber post was sectioned perpendicularly to the long axis into $61-\mathrm{mm}$ thick slices, 2 for each root canal third (coronal, medium and apical).

The thickness of the slices was measured with a digital caliper (Digimatic Caliper; Mitutoyo, accuracy of $0.01 \mathrm{~mm}$ ) and the slices were photographed on both sides with an optical microscope at $\times 40$ magnification (model BX 51; Olympus) to measure the coronal and apical diameters of the posts with the purpose of calculating their individual bonding areas. The measurement was made with the software (Image Tool version 3.0; Department of Dental Science Diagnostic).

Each slice was subjected to the push-out bond strength test using a universal loading device (AG-I; Shimadzu Autograph) at a crosshead speed of $0.5 \mathrm{~mm} / \mathrm{min}$ and $50 \mathrm{~kg}$ load. The load was applied in the apical-coronal direction until the post was dislodged. Care was taken to center the push-out pin on the center of the post surface without stressing the surrounding post space walls. Regarding the tapered design of the post, different sizes of punch pins matching the diameter of the post at the different root thirds were used.

The maximum failure load $(\mathrm{N})$ was recorded and converted into MPa by dividing the applied load by the bonded area (SL); the latter, the lateral surface of a truncated cone, was calculated by using the formula

$S_{L}=\pi(R+r)\left[\left(h^{2}+(R-r)^{2}\right]^{1 / 2}\right.$, where:

$\pi$ is the constant 3.1416, $R=$ coronal post radius, $r=$ apical post radius, and $h=$ root slice thickness.

Data obtained from the push-out test were analyzed by 3-way repeated-measures ANOVA (Rotary instrument vs. Acid application mode vs. Root third) and Tukey post-hoc test $(\alpha=0.05)$. All calculations were performed using the SPSS $\otimes$ statistical software (Statistical Package for the Social Sciences, version 21.0 Mac; SPSS Inc.).

\section{Results}

According to the SEM images (figure 1), we observed that the group DB with conventional etching presented a more homogeneous and thin smear layer in all root canal thirds in relation to the other groups. Another outcome observed was that the use of 
CBCE

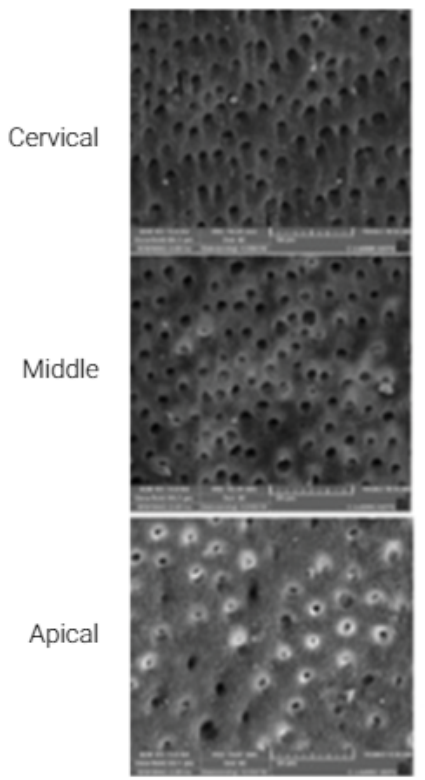

CBAE

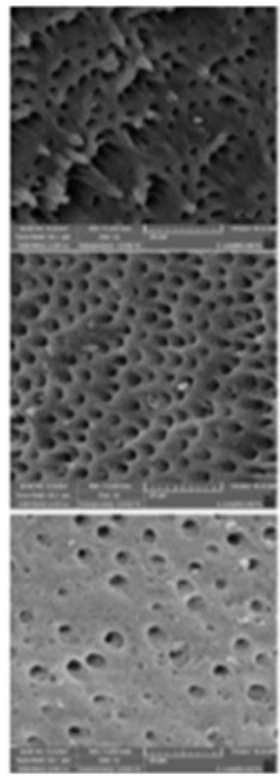

DBCE

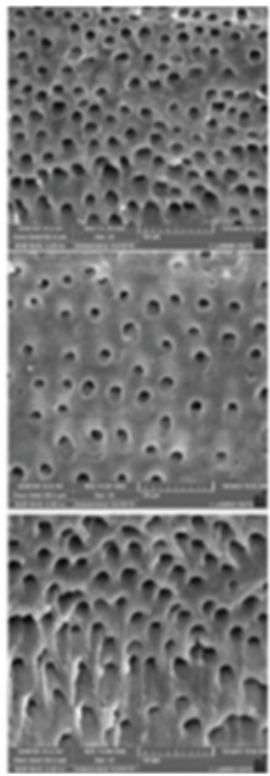

DBAE

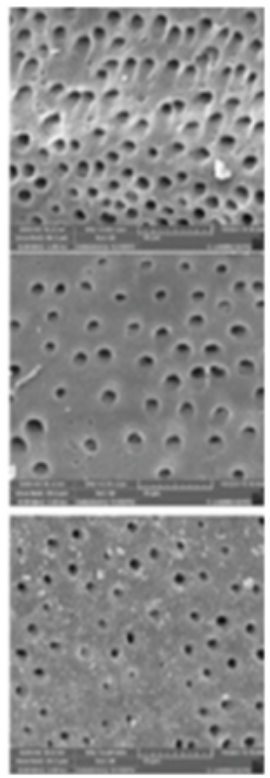

Figure 1. SEM images of the morphological ultrastructural evaluation of the different groups.

Table 1. Mean and standard deviation of bond strength (MPa) of the different groups*

\begin{tabular}{lccc}
\hline \multirow{2}{*}{$\begin{array}{l}\text { EXPERIMENTAL GROUPS } \\
(\mathrm{n}=8)\end{array}$} & \multicolumn{3}{c}{ ROOT REGION } \\
\cline { 2 - 4 } & Cervical & Medium & Apical \\
\hline CBCE & $12.1 \pm 4.4 \mathrm{~B}$ & $13.4 \pm 3.8 \mathrm{~B}$ & $6.9 \pm 2.9 \mathrm{C}$ \\
\hline CBAE & $12.3 \pm 2.7 \mathrm{~B}$ & $8.7 \pm 3.4 \mathrm{C}$ & $7.7 \pm 2.7 \mathrm{C}$ \\
\hline DBCE & $22.7 \pm 4.1 \mathrm{~A}$ & $18.4 \pm 4.0 \mathrm{~A}$ & $21.1 \pm 2.4 \mathrm{~A}$ \\
\hline DBAE & $13.8 \pm 3.3 \mathrm{~B}$ & $8.3 \pm 3.1 \mathrm{C}$ & $7.7 \pm 2.1 \mathrm{C}$ \\
\hline
\end{tabular}

* Distinct letters show statistically significant differences $(p \leq 0.05)$

CBCE - carbide bur conventional etching, CBAE - carbide bur active etching, DB - diamond bur conventional

etching, DBAE - diamond bur active etching

the ultrasonic tip in the acid application did not improve smear layer removal, resulting in a thicker smear layer in all root canal thirds, especially in the apical region.

In relation to the bond strength evaluation, the cross-product interaction among rotary instrument vs. acid application mode vs. root third was statistically significant $(p=0.035)$. The use of diamond burs (DB) to prepare the post space associated with the conventional acid etching (CE) was the technique with the highest bond strength values regardless of the root canal region. In all conditions, the diamond bur produced higher bond strength values than the carbide bur (CB) (Table 1).

\section{Discussion}

The null hypotheses of this study were rejected because both the different rotary instruments and the acid application mode influenced the push-out bond strength values of fiber posts to the root canal. 
The fiber post space is commonly prepared with tungsten carbide burs provided by the post manufacturer, which is selected based on the diameter of each glass fiber post diameter. The study demonstrated that the diamond burs tested, instead of carbide burs, associated with the conventional acid etching technique resulted in the highest bond strength values regardless of the root canal region. As seen in the SEM images (Figure 2), diamond burs produced a thicker and disorganized smear layer when compared to carbide burs, which was also demonstrated in a previous study conducted in coronal dentin ${ }^{11}$. This feature makes the smear layer produced by diamond burs easier to be removed by phosphoric acid ${ }^{11,12}$. This is possibly the reason why high bond strength values were observed in the group DB with conventional etching ${ }^{10,11}$.

On the other hand, the smear layer formed by the carbide bur was more regular, denser and smoother, which makes it more difficult to be removed by phosphoric acid etching, jeopardizing tissue demineralization and resin infiltration within the demineralized intertubular dentin ${ }^{16}$. This is responsible for the lower bond strength values observed in the carbide bur groups ${ }^{11}$. The different patterns of smear layer produced by the two different rotary instruments are due to the different mechanisms of tissue removal. While the carbide bur uses several blades that cut the root dentin, the diamond bur removes tissue by abrasion ${ }^{11}$.

Active etching, with ultrasonic activation of the etchant, was not able to produce similar results. Differently from this study, another study demonstrated that the active application of a liquid acid phosphoric agent promoted better results of push-out bond strength and improved smear layer removal ${ }^{13}$. However, in that study, the authors used an endodontic needle to agitate the etchant but not an ultrasonic tip. The different methods of active etchant agitation may explain the controversy between the present and the aforementioned study ${ }^{13}$. It is possible that the ultra-
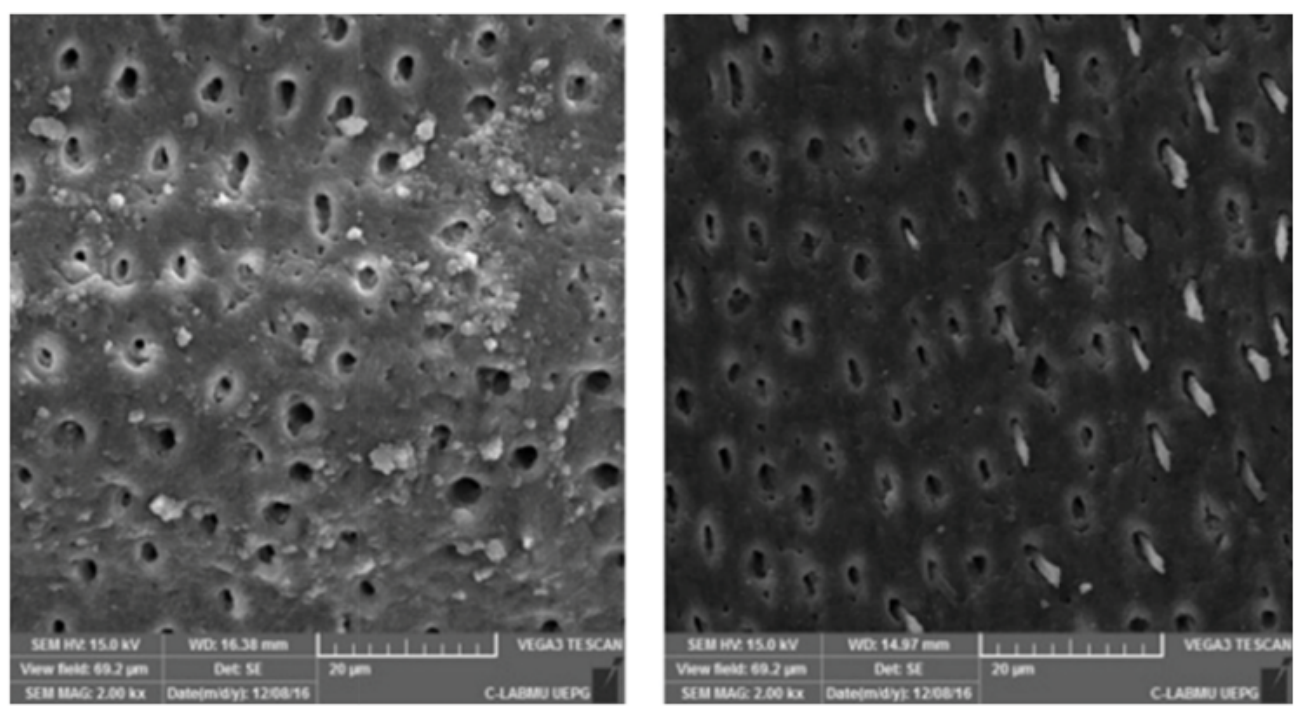

Figure 2. SEM images of the morphological ultrastructural evaluation of the differents smear layers between diamond burs and carbide burs. 
sonic tip may promote excessive demineralization, fibril collagen collapse and collagen disintegration, which in turn, may reduce adhesive penetration within the network and decrease bond strength values between the adhesive and the root dentin ${ }^{17}$. A previous study conducted on coronal dentin concluded that manual gel agitation increases the bonding performance, preserving the collagen fibrils spaces to ensure adequate monomer infiltration ${ }^{7}$. Perhaps different results could have been obtained if a sonic or manual etching agitation was performed.

In medical sciences, high-frequency ultrasound is commonly used for tumor ablation, frequencies near $1 \mathrm{MHz}$ have been found to be the most useful for heat deposition. Frequencies as low as $0.5 \mathrm{MHz}$ are used for deep treatments or with large absorption portion in the propagation path, and as high as $8 \mathrm{MHz}$ for superficial treatment. In other words, the lower the frequency is, the greater the action depth is ${ }^{18}$. The frequency of the device used in our study was $0.03 \mathrm{MHz}$; we hypothesize that the same could have occurred within the most superficial layer of the root dentin, composed mainly by organic matrix during etching. This may have been exacerbated in areas where the ultrasonic tip contacted the root dentin. Consequently, the reduction in the areas of demineralized intertubular dentin, where resin infiltration occurs, prevented the formation of a homogeneous hybrid layer, which in turn reduced bond strength values.

The same was not observed for carbide burs. Lower bond strength values were observed either in the groups with conventional or active ultrasound etching. Perhaps the denser and thicker smear layer, which was not removed to the same extent that the smear layer produced by the diamond bur (Figure 1), produced a barrier for ultrasonic action as well as resin infiltration.

Regarding the root thirds, usually lower bond strength values were observed at the most apical area, and these results are in accordance with several earlier studies ${ }^{19-21}$. The lower bond strength values in the apical third are due to poor accessibility; higher smear layer content, debris and remaining endodontic cement ${ }^{22,23}$. Fortunately, these lower bond strength values at the apical area were not observed in the group where the diamond bur was associated with the conventional etching group. This should be seen with enthusiasm - the features of the thinner smear layer produced by the diamond burs in the apical region facilitate its removal by the acid etching, positively influencing bond strength values.

The phosphoric acid formulation may also influence the adhesion between the adhesive and the root dentin. As shown by a previous study, a liquid formulation may promote higher bond strength values, regardless of the root third ${ }^{13}$. Another study found that liquid phosphoric acid only enhances bond strength in the apical third ${ }^{24}$. As noted, further studies are required to verify the use of etching active application with both formulations, especially in the apical third, as the above-mentioned studies described different application techniques of the phosphoric acid.

In conclusion, the highest bond strength values were obtained with the use of diamond burs to prepare the post space instead of carbide burs. The use of diamond burs yielded similar bond strength values at all root thirds. Activation of the phosphoric acid with an ultrasonic tip should be avoided when a diamond bur is used for post space preparation. 


\section{Acknowledgements:}

The authors are very grateful to FGM Dental Products (Brazil) for the donation of the cementation system and fiber posts employed in this study. Funding for this study was partially obtained through a productivity scholarship provided by the Araucaria Foundation.

\section{References}

1. Lassila LV, Tanner J, Le Bell AM, Narva K, Vallittu PK. Flexural properties of fiber reinforced root canals posts. Dent Mater. 2004 Jan;20(1):29-36.

2. Peutzfeldt A, Asmussen E. Modulus of resilience as predictor for clinical wear of restorative resins. Dent Mater. 1992 May;8(3):146-8.

3. Hayashi M, Ebisu S. Key factors in achieving firm adhesion in post-core restorations. Japan Dent Sci Rev. 2008 Jul;44(1):22-8. doi: 10.1016/j.jdsr.2007.10.001.

4. Qualtrough AJ, Manocci F. Tooth-colored post systems: a review. Oper Dent. 2003 Jan-Feb;28(1):86-91.

5. Parisi C, Valandro LF, Ciocca L, Gatto MR, Baldissara P. Clinical outcomes and success rates of quartz fiber post restorations: a retrospective study. J Prosthet Dent. 2015 Sep;114(3):367-72. doi: 10.1016/j.prosdent.2015.03.011.

6. Ferrari M, Vichi A, Grandini S. Efficacy of different adhesive techniques on bonding to root canal walls: an SEM investigation. Dent Mater. 2001 Sep;17(5):422-9.

7. Faria-e-Silva AL, Silva JL, Almeida TG, Veloso FB, Ribeiro SM, Andrade TD, et al. Effect of acid etching time and technique on bond strength of an etch-and-rinse adhesive. Acta Odontol Latinoam. 2011;24(1):75-80.

8. Belli R, Sartori N, Peruchi LD, Guimaraes JC, Vieira LC, Baratieri LN, et al. Effect of multiple coats of ultra-mild all-in-one adhesives on bond strength to dentin covered with two different smear layer thicknesses. J Adhes Dent. 2011 Dec;13(6):507-16. doi: 10.3290/j.jad.a19814.

9. Borges AB, da Silva MA, Borges AL, Werkman C, Torres CR, Pucci CR. Microshear bond strength of self-etching bonding systems to ultrasound diamond bur-prepared dentin. J Adhes Dent. 2011 Oct;13(5):433-8. doi: 10.3290/j.jad.a19650.

10. Sattabanasuk V, Vachiramon V, Qian F, Armstrong SR. Resin-dentin bond strength as related to different surface preparation methods. J Dent. 2007 Jun;35(6):467-75.

11. Peerzada F, Yiu CK, Hiraishi N, Tay FR, King NM. Effect of surface preparation on bond strength of resin luting cements to dentin. Oper Dent. 2010 Nov-Dec;35(6):624-33. doi: 10.2341/09-379-L.

12. Spencer P, Wang Y, Walker MP, Swafford JR. Molecular structure of acid-etched dentin smear layersin situ study. J Dent Res. 2001 Sep;80(9):1802-7.

13. Scotti N, Scansetti M, Rota R, Breschi L, Mazzoni A, Pasqualini D, et al. Active application of liquid etching agent improves adhesion of fiber posts to intraradicular dentine. Int Endod J. 2013 Nov;46(11):1039-45. doi: 10.1111/iej.12096.

14. Cameron JA. Factors affecting the clinical efficiency of ultrasonic endodontics: a scanning electron microscopy study. Int Endod J. 1995 Jan;28(1):47-53.

15. Guerisoli DMZ, Marchesan MA, Walmsley AD, Lumley PJ, Pecora JD. Evaluation of smear layer removal by EDTAC and sodium hypochlorite with ultrasonic agitation. Int Endod J. 2002 May;35(5):418-21. 
16. Yiu CKY, Hiraishi N, King NM, Tay FR. Effect of dentinal surface preparation on bond strength of self-etch adhesives. J Adhes Dent. 2008 Jun;10(3):173-82.

17. Breschi L, Mazzoni A, Ruggeri A, Cadenaro M, Di Lenarda R, De Stefano Dorigo E. Dental adhesion review: aging and stability of the bonded interface. Dent Mater. 2008 Jan;24(1):90-101.

18. Zhou YF. High intensity focused ultrasound in clinical tumor ablation. World J Clin Oncol. 2011 Jan 10;2(1):8-27. doi: 10.5306/wjco.v2.i1.8.

19. Menezes MS, Queiroz EC, Campos RE, Martins LR, Soares CJ. Influence of endodontic sealer cement on fibreglass post bond strength to root dentine. Int Endod J. 2008 Jun; 41(6):476-84. doi: 10.1111/j.1365-2591.2008.01378.x.

20. Ohlmann B, Fickenscher F, Dreyhaupt J, Rammelsberg P, Gabbert O, Schmitter M. The effect of two luting agents, pretreatment of the post, and pretreatment of the canal dentin on the retention of fiber-reinforced composite posts. J Dent. 2008 Jan;36(1):87-92.

21. Pulido CA, de Oliveira Franco AP, Gomes GM, Bittencourt BF, Kalinowski HJ, Gomes JC, et al. An in situ evaluation of the polymerization shrinkage, degree of conversion, and bond strength of resin cements used for luting fiber posts. J Prosthet Dent. 2016 Oct;116(4):570-576. doi: 10.1016/j.prosdent.2016.02.019.

22. Gomes GM, Rezende EC, Gomes OMM, Gomes JC, Loguercio AD, Reis A. Influence of the resin cement thickness on bond strength and gap formation of fiber posts bonded to root dentin. J Adhes Dent. 2014 Feb;16(1):71-8. doi: 10.3290/j.jad.a30878.

23. Serafino C, Gallina G, Cumbo E, Ponticelli F, Goracci C, Ferrari M. Ultrasound effects after post space preparation: an SEM study. J Endod. 2006 Jun;32(6):549-52.

24. Salas MM, Bocangel JS, Henn S, Pereira-Cenci T, Cenci MS, Piva E, et al. Can viscosity of acid etchant influence the adhesion of fibre posts to root canal dentine? Int Endod J. 2011 Nov;44(11):1034-40. doi: 10.1111/j.1365-2591.2011.01918.x. 